\title{
Composite Design of Low Thermal Conductivity Mullite Brick for Application to Cement Kiln
}

\author{
Songlin Chen ${ }^{1,3}$, Juntao Wang ${ }^{1, \mathrm{~b}}$, Lin Yuan ${ }^{1,2}{ }^{*}$, and Quanyou $\mathrm{Li}^{2}$ \\ ${ }^{1}$ Ruitai Materials Technology Co., Ltd., China Building Materials Academy, Beijing China, 100024 \\ ${ }^{2}$ Zhengzhou Ruitai Materials Technology Co., Ltd, Zhengzhou Henan China, 452374 \\ ${ }^{3}$ Yixing Refractories Co., Ltd., Yixing Jiangsu China, 214264
}

\begin{abstract}
In order to restrain cement kiln shell's thermal loss and potential safety hazard, composite design is employed of working layer, thermal-preservation layer and thermal insulation layer. Thermalpreservation layer's boundary and strain is analyzed and overall thermal conductivity is calculated. The result shows that sinusoidal curve boundary combination between working layer and thermal-preservation layer, slopeshape with angle of 135 degrees between thermal-preservation layer and thermal insulation layer could relieve strain concentration. Composite mullite brick comprehensive thermal conductivity decreases from the working layer $2.74 \mathrm{~W} \cdot \mathrm{m}^{-1} \cdot \mathrm{K}^{-1}$ to $1.50 \mathrm{~W} \cdot \mathrm{m}^{-1} \cdot \mathrm{K}^{-1}$. When applied in cement kiln, temperature of kiln shell is lower $50^{\circ} \mathrm{C}$ to $70^{\circ} \mathrm{C}$ than using normal bricks.
\end{abstract}

\section{Introduction}

Cement rotary kiln is high energy consumption mechanical equipment. Especially in the latter and upper transition zone, refractory bricks directly contact with clinker without the preservation of coating. Higher thermal conductivity leads to high temperature of kiln shell, high heat loss and high fuel consumed, lower lifetime of tire and kiln shell. Meanwhile, under the impact of chemical corrosion and mechanical erosion, refractory is easily damaged $[1,2]$.

In order to restrain kiln shell's thermal loss and potential safety hazard, method of lower conductivity coefficient of refractory will be the first alternative. But lower conductivity coefficient method of SiC-mullite brick and Magnesia-spinel brick is limited. When choosing other materials, corrosion resistance property and environment issues should be taken into consideration. Given all that, composite designs are of considerable interest [3-6]. Multilayer mullite based brick with reduced thermal conductivity choose the method of multilayer structure with working layer, thermal-preservation layer and thermal-insulation layer. Working layer has been designed with high strength, lower thermal conductivity, high refractoriness under load, high thermal shock resistance and long lifetime; As bonding structure connecting working layer and thermal-insulation layer, thermal preservation layer

\footnotetext{
* Corresponding author: yl@bjruitai.com
} 
combines excellent high strength as well as lower thermal conductivity; thermal insulation layer use ultra-lower thermal conductivity to decrease brick's thermal conductivity.

\section{Composite design of multilayer mullite based brick with low thermal conductivity}

\subsection{Refractory in working layer}

Working layer choose andalusite-SiC-mullite brick, which is based on M70 bauxite based mullite, M70, M80 homogeneous materials and andalusite. After mixing, forming and 1490 ${ }^{\circ} \mathrm{C}$ fired, main indexes of working layer could satisfy basic requirements of transition zone $\left(\mathrm{Al}_{2} \mathrm{O}_{3} \geq 65 \%\right.$, apparent porosity $\leq 20 \%$, Bulk Density $2.65 \mathrm{~g} / \mathrm{cm}^{3}$, Cold Crushing Strength $\geq 90 \mathrm{MPa}$, Refractoriness under load $\mathrm{T}_{0.6} \geq 1620{ }^{\circ} \mathrm{C}$ ). The thermal conductivity coefficient of this area is $2.74 \mathrm{~W} \cdot \mathrm{m}^{-1} \cdot \mathrm{K}^{-1}$.

\subsection{Refractory in thermal-preservation layer.}

Aiming for lowing overall thermal conductivity, this layer should share lower conductivity coefficient than working layers, have adhesive ability with working layer, as well as excellent cold modulus of rupture and abrasion resistance. This layer is based on M60 bauxite based mullite, clay, $\mathrm{Al}_{2} \mathrm{O}_{3}$ powder and silicon micro-powder. Then hightemperature fired contributes to the formation of mullite phase, which guaranteed high strength and similar expansion coefficient and linear change on reheating with working layers. Then formed mullite phases obvious reduced thermal conductivity, and micropowders could produce closed pores in the intern structure, which further decrease thermal conductivity $[7,8]$. The thermal conductivity of this layer is $1.58 \mathrm{~W} \cdot \mathrm{m}^{-1} \cdot \mathrm{K}^{-1}$.

\subsection{Refractory in thermal-Insulation layer}

The ultimate quality of multilayer mullite based brick with reduced thermal conductivity is directly influenced by the quality of thermal-insulation layers. This layer is composed of zirconia ceramic fibers of high refractoriness and working accuracy, the thermal conductivity coefficient is $0.12 \mathrm{~W} \cdot \mathrm{m}^{-1} \cdot \mathrm{K}^{-1}$.

\subsection{Thickness and shape design of multilayer brick.}

\subsubsection{Thickness design of different layers}

In order to ensure lifetime and operation rate of cement kiln, when residue thickness is less than $1 / 3$ after erosion and abrasion, kiln must be stopped to maintenance. Therefore, the thickness of working layer is $70 \%$ of total thickness. The thickness of working layer is $0.140 \mathrm{~m}$, thermal-preservation layer is $0.035 \mathrm{~m}$, and thermal-insulation layer is $0.025 \mathrm{~m}$.

\subsubsection{Shape-design of thermal preservation layer}

The preservation layer is located between working layer and thermal insulation layer, which two faces of preservation layer connect with the other two layers. Therefore, thermal strain concentration should be taken into consideration. 


\subsubsection{Boundary-shape design between thermal-insulation layer and thermal- preservation layer}

The heat preservation performance of multilayer bricks is not only related to thickness of materials used in thermal insulation layer and thermal preservation layer, but also related to the area of materials. Furthermore, the thermal preservation layer has capability of burdening load. Therefore, the thickness of thermal-insulation layer is proportional to heat preservation layer, but weaker the brace parts. Numerous trials have shown that open-shape area of brace, as shown in Fig.1, is one third of overall area, extending to inside at the angle of $135^{\circ}$.

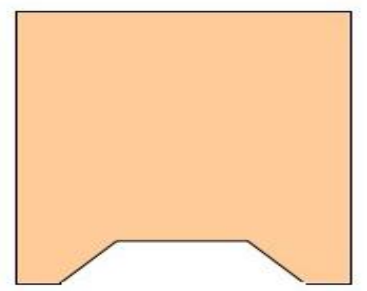

Fig.1. Open shape of thermal preservation layer

\subsubsection{Boundary shape design}

Materials in thermal-preservation layer and working layer have similar composition, physical properties. This leads to excellent binding, cold modulus of rupture and abrasionresistance. Therefore, boundary is designed sinusoidal curve boundary combination, as shown in Fig.2.

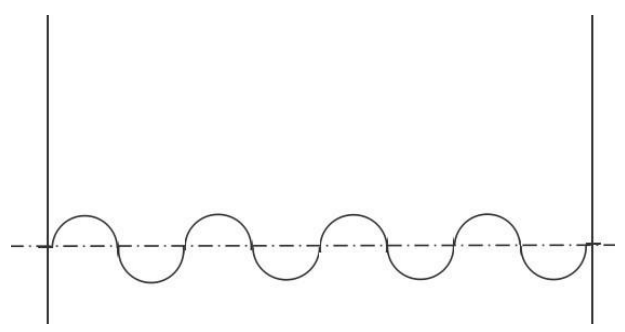

Fig.2. Sinusoidal curve boundary of working layer and thermal-preservation layer

Therefore physical design of multilayer brick is shown in Fig3. Boundary of working layer and thermal-preservation layer is sinusoidal curve design, with the angle of $135^{\circ}$.

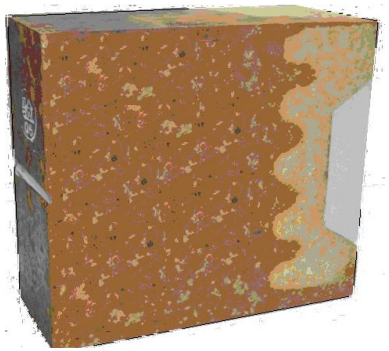

Fig.3. Multilayer mullite based brick with reduced thermal conductivity 


\subsubsection{Strain analysis of structure in thermal- preservation layer}

When thermal-preservation layer is influenced by vertical strain caused by gravity of clinker, strain from central part and two edges could be dissipated along angle of $45^{\circ}$, as shown in Fig4. The central part will not be damaged by strain.

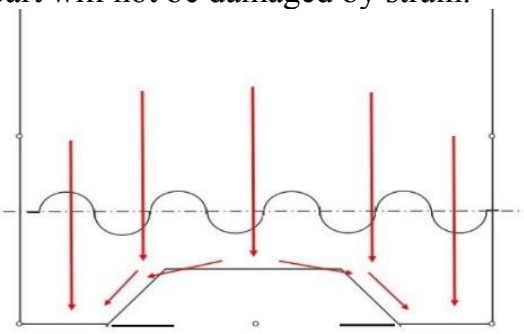

Fig.4. Vertical strain on thermal-preservation layer

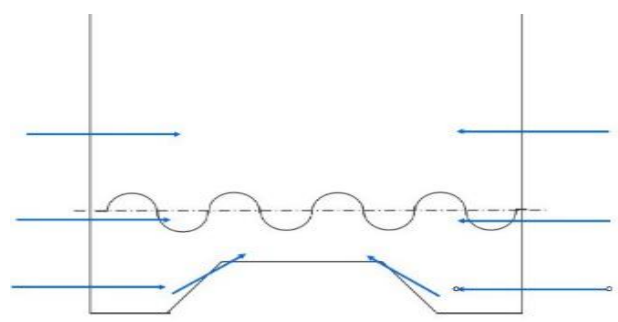

Fig.5. Transverse expansion stress analysis

When thermal-preservation layer is squeezed by transverse expansion stress between bricks, the pressure of foothold is diffused along $45^{\circ}$, as shown in Fig.5, reduces the rates of foothold parts' fracture.

When circumferential shear loads impact on thermal-preservation layer, angle of $45^{\circ}$ contribute to increased contact area 50\% (as shown in Fig.6), which decrease the possibility of crack caused by circumferential shear loads on brace parts.

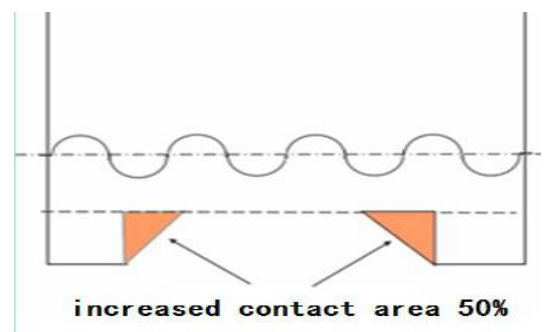

Fig.6. Circumferential shear loads analysis

\section{Comprehensive thermal conductivity coefficient calculations}

According to heat transfer calculation formula,

$$
q=\frac{\lambda}{\delta} \cdot \Delta T
$$


Under the circumstance of multilayer,

$$
q=\frac{\Delta T}{\sum_{i=1}^{n} \frac{\delta_{i}}{\lambda_{i}}}
$$

In formula (1) and (2), $q$ is quantity of heat, $\delta$ is thickness of different layers, $\lambda$ is thermal conductivity of different layers, $\Delta T$ is temperature difference. Considering formula (1) and (2), thermal conductivity of multilayer brick can be described as formula (3),

$$
\lambda_{\text {compound }}=\frac{\delta}{\sum_{i=1}^{n} \frac{\delta_{i}}{\lambda_{i}}}
$$

For the thickness of first layer is $0.14 \mathrm{~m}$, thermal conductivity is $2.74 \mathrm{~W} \cdot \mathrm{m}^{-1} \cdot \mathrm{K}^{-1}$; thickness of second layer is $0.035 \mathrm{~m}$, thermal conductivity is $1.58 \mathrm{~W} \cdot \mathrm{m}^{-1} \cdot \mathrm{K}^{-1}$; while thickness of third layer is $0.025 \mathrm{~m}$, thermal conductivity coefficient is $0.113 \mathrm{~W} \cdot \mathrm{m}^{-1} \cdot \mathrm{K}^{-1}$. Therefore the overall thermal conductivity is $1.50 \mathrm{~W} \cdot \mathrm{m}^{-1} \cdot \mathrm{K}^{-1}$.

When multilayer bricks applied in cement kiln system, the situation is quite like cylinder thermal loss. If the radius of kiln system is $d_{l}=2.4 \mathrm{~m}$, while the first layer radius is $d_{2}=2.54 \mathrm{~m}$, the second layer radius $d_{3}=2.575 \mathrm{~m}$, the third layer radius $\mathrm{d} 4=2.6 \mathrm{~m}$. Assumed that temperature of kiln system is $T_{l}=1300^{\circ} \mathrm{C}$, room temperature $T_{2}=25^{\circ} \mathrm{C}$ 。

Assumed that kiln shell temperature is $T_{3}$, so heat dissipating capacity can be calculated as formula (4),

$$
q_{\text {inner }}=\frac{2 \pi \sum_{i=1}^{n}\left(t_{n}-t_{n+1}\right)}{\sum_{i=1}^{n} \frac{1}{\lambda_{n}} \ln \frac{r_{n+1}}{r_{n}}}=\frac{2 \pi\left(T_{\text {inner }}-T_{\text {shell }}\right)}{2}
$$

Heat dissipating capacity of kiln shell is

$$
q_{\text {external environment }}=a\left(T_{\text {shell }}-T_{\text {external environment }}\right) \pi d_{4}
$$

When heat dissipating capacity reach balanced situation,

$$
q_{\text {inner }}=q_{\text {external environment }}
$$

Presumed that coefficient of convective heat transfer is $38 \mathrm{~W} \cdot \mathrm{m}^{-1} \cdot \mathrm{K}^{-1}$. After calculation, Temperature $T_{\text {shell }}$ is $290^{\circ} \mathrm{C}$, lower about $60^{\circ} \mathrm{C}$ than normal kiln shell temperature $\left(350^{\circ} \mathrm{C}\right)$.

\section{Applied to cement application}

In July 2013, Multilayer mullite based brick with reduced thermal conductivity used in area of 37 to 47 meters in cement rotary kiln of Dequan Jilin. Temperature of kiln shell is $200^{\circ} \mathrm{C}$ after using one week; while the temperature is after $220^{\circ} \mathrm{C}$ using one month, the temperature is $230^{\circ} \mathrm{C}$ after using two months. If normal bricks used in cement furnace, the 
average temperature is $370^{\circ} \mathrm{C}$. As conclusion Multilayer brick could lower kiln shell temperature more than $100^{\circ} \mathrm{C}$, substantially abate thermal loss and decrease the possibility about elevated temperature of kiln shell. Due to thermal preservation effects after several months' usage condition, widespread use leads to better thermal preservation effects.

\section{Conclusions}

1) Sinusoidal boundary and $135^{\circ}$ shape design, which avoid thermal preservation layer's strain concentration, and avoid broken of supporting legs.

2) Composite design of working layer, thermal preservation layer and thermal insulation layer is employed to lower thermal conductivity $\left(2.74 \mathrm{~W} \cdot \mathrm{m}^{-1} \cdot \mathrm{K}^{-1}\right.$ to $1.50 \mathrm{~W} \cdot \mathrm{m}^{-1} \cdot \mathrm{K}^{-}$ $\left.{ }^{1}\right)$;

3) When multilayer brick has been chosen in transitional zone of cement furnace, the kiln shell temperature is lower about $60^{\circ} \mathrm{C}$ (rang from $50^{\circ} \mathrm{C}$ to $70^{\circ} \mathrm{C}$ ).

The authors would like to thank the financial support from the National Key Technology Research and Development Program of China (No.2013BAE03B01-10) and Yixing Key Research and Development Plan (No.YGB2016020).

\section{References}

1. Q. S. Zhou. Preparation of SiC/mullite/alumina composite ceramic. D. Central South University: (2001).(In Chinese)

2. F. Yao, Z. Y. Liu. China Non-metallic Mining Industry. J. 6, 8 (2013) (In Chinese)

3. L, Yuan, X. F. Chen. Naihuo Cailiao. J. 50, 161 (2016). (In Chinese)

4. Z. Y. Liu, B. Xu. J. of Materials Science \& Engineer. J. 32, 85 (2014). (In Chinese)

5. J. Z. Wang, L. Yuan. Naihuo Cailiao. J48, 161 (2014). (In Chinese)

6. S. J. Chen Research on thermo mechanical stress of ladle composite structure and its life prediction. D. Wuhan: Wuhan University of Science and Technology, 2007. (In Chinese)

7. J. F. Chen, H. Z. Zhao. Naihuo Cailiao. J. 49, 120 (2015). (In Chinese)

8. X. Hou, Q. H. Xue.. Bulletin of the Chinese ceramic society. J. 34, 2325 (2015). (In Chinese) 